Arq. Bras. Med. Vet. Zootec., v.66, n.2, p.505-509, 2014

\title{
Desenvolvimento de bezerros leiteiros alimentados com silagem de leite de transição. II - Órgãos internos
}

\author{
[Development of dairy calves fed silage transition milk. II - Internal organs] \\ R.A. Azevedo ${ }^{1}$, D.V.L. Duarte ${ }^{2}$, A.C.M. Soares ${ }^{2}$, N.J.F. Oliveira $^{2}$, S.G. Coelho ${ }^{1}$, \\ E.R. Duarte ${ }^{2}$, L.C. Geraseev ${ }^{2}$ \\ ${ }^{1}$ Escola de Medicina Veterinária - EV/UFMG - Belo Horizonte, MG \\ ${ }^{2}$ Instituto de Ciências Agrárias - ICA/UFMG - Montes Claros, MG
}

\section{RESUMO}

Avaliou-se o tamanho absoluto e relativo dos órgãos internos de bezerros Holandeses aleitados com leite, silagem de leite de transição diluída em água ou misturada em leite. Foram utilizados 18 animais, machos, com 60 dias de idade e peso corporal médio de $70,3 \mathrm{~kg}( \pm 11,8 \mathrm{~kg})$. O delineamento experimental foi inteiramente ao acaso, com três tratamentos e seis repetições. Os animais foram abatidos aos dois meses de idade, sendo previamente submetidos a jejum alimentar de 16 horas. $\mathrm{O}$ aleitamento modificou os pesos dos órgãos internos e da gordura omental dos animais, exceto para rins e gordura mesentérica, e não alterou o consumo de alimentos sólidos. A silagem de leite de transição diluída em água comprometeu o desempenho dos bezerros, refletindo no peso dos órgãos internos e de gordura omental, e apresentou pesos absolutos para fígado, baço e gordura omental de 1.072, 186 e 133g, respectivamente. A silagem misturada em leite proporcionou resultados mais semelhantes ao fornecimento exclusivo de leite, demonstrando-se como opção para o aleitamento de bovinos jovens.

Palavras-chave: bezerro, fermentação, gordura, leite, metabolismo, sucedâneo

\begin{abstract}
This study aimed to evaluate the absolute and relative size of internal organs of Holstein calves which suckled milk, silage transition milk diluted with water or mixed in milk. We used 18 male animals, 60 days old with a mean body weight of $70.3 \mathrm{~kg}( \pm 11.8 \mathrm{~kg})$. The experimental design was completely randomized with three treatments and six replications. The animals were slaughtered at two months, and previously fasted for 16 hours. Breast feeding changed the weights of internal organs and omental fat of animals, except for kidney and mesenteric fat, and did not affect food intake solids. The silage transition milk diluted in water compromised the performance of the calves, reflecting on the weight of internal organs and omental fat, and showed absolute weights for liver, spleen and omental fat of 1072, 186 and $133 \mathrm{~g}$, respectively. The silage mixed with milk yielded results more similar to the exclusive milk supply, being an option for suckling calves.
\end{abstract}

Keywords: calf, fat, fermentation, metabolism, milk, milk replacer

\section{INTRODUÇÃO}

Grande parte das fazendas produtoras de leite no Brasil criam os bezerros de forma inadequada e não dispensam cuidados especiais às fêmeas. Já os machos são, em sua maioria, sacrificados ao nascer, em razão do alto custo da dieta líquida, constituída de leite integral, durante a fase em que as crias são consideradas não ruminantes (Campos, 1985). Pressões econômicas geram

Recebido em 22 de fevereiro de 2013

Aceito em 12 de setembro de 2013

E-mail: rafaelzooufmg@gmail.com avanços das técnicas alimentares e de manejo na fase de cria, pois o leite utilizado pode ocasionar desvios de recursos e reduzir a lucratividade do sistema (Castro et al., 2004), devendo ser substituído por alimentos de boa qualidade.

Empregar o leite de transição excedente na alimentação de bezerros pode constituir alternativa racional (Arguello et al., 2003; Saalfeld et al., 2013) e viável (Ribeiro et al., 2001; Saalfeld, 2008; Azevedo et al., 2013); 
porém, o armazenamento desse produto não comercializável pode ser oneroso. $\mathrm{O}$ acondicionamento anaeróbico do colostro e do leite de transição excedente em garrafas plásticas de politereftalato de etilenotipo (PET) foi proposto por Saalfeld (2008), sendo conhecido como silagem de colostro.

Por não participar da composição da carcaça, existem poucos estudos sobre o desenvolvimento esplâncnico de bovinos. No entanto, essas variáveis podem influenciar diretamente o rendimento comercial (Carvalho et al., 2003), além de estarem associadas às diferenças nas exigências nutricionais de mantença dos animais (Rocha, 1997), o que pode relacionar-se com o melhor e correto desenvolvimento futuro dos animais.

Objetivou-se avaliar o desenvolvimento de órgãos internos de bezerros Holandeses alimentados com silagem de leite de transição diluída em água ou misturada em leite.

\section{MATERIAL E MÉTODOS}

O experimento foi aprovado pelo Comitê de Ética em Experimentação Animal da Universidade Federal de Minas Gerais.

Foram utilizados 18 bezerros da raça Holandesa, com peso corporal inicial médio de $36,50 \pm 4,03 \mathrm{~kg}$, distribuídos em delineamento inteiramente ao acaso, com três tratamentos e seis repetições. Os animais foram mantidos em baias individuais, equipadas com baldes para fornecimento de água, concentrado, feno e suplemento mineral.

Após o nascimento, os bezerros permaneceram com as matrizes por $24 \mathrm{~h}$ para ingerirem colostro ad libitum. Em seguida, foram identificados $\mathrm{e}$ alojados no galpão experimental. No segundo dia de vida, foram alimentados com quatro litros de colostro de suas respectivas mães, às $8 \mathrm{~h}$ e às $16 \mathrm{~h}$.

Os animais dos dois grupos aleitados com silagem de leite de transição foram adaptados à dieta, acrescentando-se 12,5, 25 e 37,5\% da silagem ao leite, respectivamente, no terceiro, quarto e quinto dias de idade, como indicado por Saalfeld (2008).
A partir do sexto dia, as dietas foram ofertadas em volume de quatro litros, correspondentes aos tratamentos: leite, silagem de leite de transição diluída em água na proporção de 1:1 e silagem de leite de transição diluída em leite na proporção 1:1. Todos os grupos foram alimentados em duas refeições diárias de volume equivalente, às oito e às $16 \mathrm{~h}$.

Pela manhã foi trocada a água, e à tarde foram renovados o concentrado peletizado e o feno de tifton (Cynodon spp.), sendo ofertados ad libitum, em comedouros de plástico, ajustando-se as sobras em $200 \mathrm{~g} \mathrm{~kg}^{-1}$. O suplemento mineral foi fornecido ad libitum.

O leite foi obtido de vacas Holandesas de diferentes ordens e períodos de lactação. A secreção láctea de transição foi coletada conforme Saalfeld (2008), do terceiro ao sexto dia após o parto.

A composição do concentrado, do feno, do leite e da silagem de leite de transição, bem como os procedimentos metodológicos de abate foram relatados por Azevedo et al. (2014).

Procedeu-se à análise estatística em delineamento inteiramente casualizado para as variáveis de peso corporal final, peso corporal vazio e dos órgãos internos, expressos de forma absoluta ou relativa, sendo aplicado o teste de Tukey a 5\% de probabilidade (Statistical..., 2002). O peso corporal inicial dos bezerros foi utilizado como covariável.

\section{RESULTADOS E DISCUSSÃO}

Aspectos deste experimento relacionados ao desenvolvimento do trato digestivo foram publicados em Azevedo et al. (2014).

Animais alimentados com silagem de leite de transição aceitaram normalmente o alimento após o período de adaptação. Saalfeld (2008) observou rejeição quando o fornecimento foi realizado sem diluição em água. Ferreira et al. (2013) relatou recusa pelos bezerros durante o fornecimento de dois litros de silagem de colostro diluída em água, nas primeiras semanas de idade. 
O sistema de aleitamento não interferiu $(\mathrm{P}>0,05)$ no consumo médio de concentrado, feno e matéria seca total (Tab. 1). De acordo com Ferreira et al. (2013), o fornecimento da silagem de colostro diluída em água reduziu o consumo de concentrado para $230 \mathrm{~g} \mathrm{dia}^{-1}$, valor menor que o observado neste trabalho (Tab. 1).

Tabela 1. Médias de consumos de concentrado (CC), feno (CF) e total de matéria seca (CMST) de bezerros Holandeses criados em diferentes sistemas de aleitamento artificial até 59 dias de idade

\begin{tabular}{cccccc}
\hline Variável & Leite & Silagem em água & Silagem em leite & EPM $^{1}$ & $P$ \\
\hline $\mathrm{CC}\left(\mathrm{g} \mathrm{dia}^{-1}\right)$ & 598,20 & 513,90 & 461,20 & 43,70 & 0,46 \\
$\mathrm{CF}\left(\mathrm{g} \mathrm{dia}^{-1}\right)$ & 92,54 & 76,89 & 139,53 & 12,98 & 0,12 \\
$\mathrm{CTMS}\left(\mathrm{g} \mathrm{dia}^{-1}\right)$ & 612,00 & 523,50 & 521,30 & 43,53 & 0,68
\end{tabular}

${ }^{1} \mathrm{EPM}=$ Erro Padrão da Média. * Médias seguidas de letras diferentes na linha diferem entre si.

As dietas interferiram $(\mathrm{P} \leq 0,05)$ nos pesos corporais final e vazio, pesos absolutos do fígado, pulmões, baço e coração, além dos pesos absoluto e relativo da gordura omental (Tab. 2).

O menor desempenho apresentado pelos animais aleitados com silagem de leite de transição diluída em água demonstra que esse alimento fornecido como dieta líquida exclusiva pode não ser boa opção para aleitamento de bezerros. Ao diluir esse alimento, os animais recebem metade dos constituintes originais contidos nas garrafas, bem menos que os contidos no leite integral (Azevedo et al., 2014) e, consequentemente, consomem energia e proteína abaixo do mínimo necessário para o adequado crescimento e mantença, além de não apresentarem maior consumo de alimentos sólidos como forma de atendimento de parte das exigências nutricionais (Tab. 1).

Tabela 2. Valores médios dos pesos corporal final (PCF), vazio (PCVZ) e dos pesos absolutos em gramas (g) e relativos em porcentagem $(\%)$ de órgãos, vísceras e gordura interna de bezerros Holandeses, aleitados com diferentes dietas, aos 60 dias de idade

\begin{tabular}{cccccc}
\hline Variável & Leite & Silagem em água & Silagem em leite & EPM $^{1}$ & $P$ \\
\hline PCF (kg) & $78,33 \mathrm{a}$ & $61,46 \mathrm{~b}$ & $71,13 \mathrm{ab}$ & 2,77 & 0,01 \\
PCVZ (kg) & $71,13 \mathrm{a}$ & $53,39 \mathrm{~b}$ & $63,60 \mathrm{ab}$ & 2,70 & 0,01 \\
Fígado (g) & $1580,70 \mathrm{a}$ & $1072,00 \mathrm{~b}$ & $1490,8 \mathrm{a}$ & 71,20 & 0,01 \\
Fígado (\% PCVZ) & 2,28 & 2,22 & 2,11 & 0,06 & 0,25 \\
Pulmões (g) & $829,16 \mathrm{a}$ & $637,93 \mathrm{~b}$ & $804,57 \mathrm{ab}$ & 32,25 & 0,01 \\
Pulmões (\% PCVZ) & 1,17 & 1,22 & 1,25 & 0,04 & 0,68 \\
Baço (g) & $435,70 \mathrm{ab}$ & $186,30 \mathrm{~b}$ & $509,50 \mathrm{a}$ & 60,26 & 0,04 \\
Baço (\% PCVZ) & 0,63 & 0,37 & 0,81 & 0,10 & 0,09 \\
Coração (g) & $458,47 \mathrm{a}$ & $353,55 \mathrm{~b}$ & $418,97 \mathrm{ab}$ & 21,22 & 0,01 \\
Coração (\% PCVZ) & 0,65 & 0,65 & 0,68 & 0,02 & 0,95 \\
Rins (g) & 334,81 & 283,94 & 327,57 & 13,53 & 0,15 \\
Rins (\% PCVZ) & 0,47 & 0,53 & 0,52 & 0,01 & 0,23 \\
Pâncreas (g) & 74,44 & 72,90 & 67,99 & 4,60 & 0,84 \\
Pâncreas (\% PCVZ) & 0,10 & 0,13 & 0,11 & 0,01 & 0,11 \\
Gordura omental (g) & $330,33 \mathrm{a}$ & $133,00 \mathrm{~b}$ & $282,17 \mathrm{a}$ & 32,12 & 0,02 \\
Gordura omental (\% PCVZ) & $0,47 \mathrm{a}$ & $0,25 \mathrm{~b}$ & $0,41 \mathrm{ab}$ & 0,04 & 0,05 \\
Mesentério mais gordura (g) & 431,33 & 213,00 & 457,83 & 45,85 & 0,08 \\
Mesentério mais gordura (\% PCVZ) & 0,61 & 0,42 & 0,66 & 0,05 & 0,17 \\
\hline
\end{tabular}

${ }^{1} \mathrm{EPM}=$ Erro Padrão da Média. "Médias seguidas de letras diferentes na linha diferem entre si. As médias de peso absoluto de pulmões, coração, rins e pâncreas foram ajustadas para a covariável peso ao nascimento $(\mathrm{P} \leq 0,05)$.

O fígado apresentou pesos absolutos similares $(\mathrm{P}>0,05)$ entre os animais que receberam leite $\mathrm{e}$ silagem misturada em leite, os quais foram maiores do que os pesos dos bezerros alimentados com silagem diluída em água
$(\mathrm{P} \leq 0,05)$, demonstrando efeito negativo da diluição na composição nutricional da silagem. Os órgãos internos apresentam elevadas taxas metabólicas e principalmente o fígado responde a alterações alimentares (Ferrell e Jenkins, 1998), 
conforme observado neste trabalho. Segundo Owens et al. (1993), o fígado tende a aumentar o peso corporal em animais mantidos com dietas mais energéticas. Peron et al. (1993) verificaram peso do fígado proporcional ao peso corporal vazio reduzido em animais submetidos a baixo nível nutricional.

Os pesos absolutos de pulmões e coração foram maiores $(\mathrm{P} \leq 0,05)$ nos animais que receberam leite em comparação aos tratados com silagem em água. Os animais aleitados com silagem misturada em leite não apresentaram diferenças significativas em relação aos outros grupos avaliados. Esse resultado, possivelmente, ocorreu em reflexo ao observado para os pesos corporais final e vazio dos animais (Tab. 2). Mesmo alimentados com níveis nutricionais insuficientes, por longos períodos, os animais tendem a manter a integridade do coração e dos pulmões, demonstrando a prioridade na utilização dos nutrientes para esses órgãos (Ferreira et al., 2000), o que não foi verificado no presente trabalho. Melo et al. (2007) constataram peso absoluto do coração semelhante em tratamentos com ou sem restrição alimentar para bezerros leiteiros, entretanto verificaram alteração no peso absoluto dos pulmões. Castro et al. (2004) observaram pesos similares de baço, coração, fígado, pulmões e rins para animais alimentados com colostro fermentado e acondicionado de forma aeróbica, adicionado ou não com óleo de soja e zeranol.

O peso do baço dos animais aleitados com silagem de leite de transição diluída em água foi menor que o dos animais aleitados com silagem misturada em leite. Animais aleitados exclusivamente com leite não apresentaram diferenças significativas em relação aos outros grupos. $\mathrm{O}$ baço possui atividade metabólica elevada, explicada pela fisiologia de armazenamento de sangue, remoção do ferro da hemoglobina, produção de linfócitos e anticorpos (Getty et al., 1975).

A gordura interna diferiu $(\mathrm{P} \leq 0,05)$ entre os tratamentos. Animais alimentados com leite apresentaram peso relativo de gordura omental semelhante ao dos que receberam silagem misturada em leite, o qual não diferiu dos animais alimentados com silagem diluída em água. Quando expresso de forma absoluta, o peso da gordura omental dos animais aleitados com leite ou silagem misturada em leite foi mais elevado se comparado ao dos bezerros alimentados com silagem diluída em água (Tab. 2), demonstrando que misturar a silagem em leite garante maior disponibilidade de energia na dieta em relação à diluição em água. Animais que consomem mais energia podem apresentar maior tamanho relativo dos órgãos internos (Ribeiro et al., 2001), e a maior quantidade de gordura indica aumento da reserva de tecido adiposo (Silper, 2012), ou seja, o fornecimento de leite ou de silagem misturada em leite constitui-se boa reserva energética para bezerros jovens.

\section{CONCLUSÕES}

O fornecimento de silagem de leite de transição diluída em água comprometeu o desempenho corporal final dos bezerros e resultou em menores pesos dos órgãos internos e de gordura interna. A silagem de leite de transição misturada em leite proporcionou resultados semelhantes aos de animais tratados com leite, demonstrandose como opção para uso na dieta de bovinos jovens em aleitamento.

\section{AGRADECIMENTOS}

À Fazenda Experimental Professor Hamilton de Abreu Navarro (FEHAM) do ICA/UFMG. Ao suporte financeiro do Conselho Nacional de Desenvolvimento Científico e Tecnológico (CNPq), da Fundação de Amparo à Pesquisa do Estado de Minas Gerais (FAPEMIG) e da empresa Tecnutri Tecnologia em Nutrição Animal.

\section{REFERÊNCIAS}

ARGUELLO, A.; CASTROA, N.; CAPOTEB, J. et al. Effects of refrigeration, freezing-thawing and pasteurization on IgG goat colostrums preservation. Small Rumin. Res., v.48, p.135139, 2003.

AZEVEDO, R.A.; ARAÚJO, L.; COELHO, S.G. et al. Desempenho de bezerros alimentados com silagem de leite de transição. Pesqui. Agropec. Bras., v.48, p.545-552, 2013.

AZEVEDO, R.A.; RUFINO, S.R.A.; CRUZ, M.S. et al. Desenvolvimento de bezerros leiteiros alimentados com silagem deleite de transição. I Trato digestivo. Arq. Bras. Med. Vet. Zootec., v.66, p.489-496, 2014. 
CARVALHO, P.A.; SANCHEZ, L.M.B.; VIÉGAS, J. Desenvolvimento de estômago de bezerros holandeses desaleitados precocemente. Rev. Bras. Zootec., v.32, p.1461-1468, 2003.

CAMPOS, O.F. Criação de bezerros até a desmama. Doc., 14. EMBRAPA/CNPGL. Coronel Pacheco. 1985. p.5-63.

CASTRO, A.L.M.; CAMPOS, W.E.; MANCIO, A.B. et al. Desempenho e rendimento de carcaça de bezerros alimentados com colostro fermentado, associado ao óleo de soja e zeranol. Arq. Bras. Med. Vet. Zootec., v.56, p.193-201, 2004.

FERREIRA, L.S.; BITTAR, C.M.M.; SILVA, J.T.; et al. Desempenho e parâmetros sanguíneos de bezerros leiteiros que receberam sucedâneo lácteo ou silagem de colostro. Arq. Bras. Med. Vet. Zootec., v.65, p.1357-1366, 2013.

FERREIRA, M.A.; VALADARES FILHO, S.C.; MUNIZ, E.B. et al. Características das carcaças, biometria do trato gastrintestinal, tamanho dos órgãos internos e conteúdo gastrintestinal de bovinos F1 Simental x Nelore alimentados com dietas contendo vários níveis de concentrado. Rev. Bras. Zootec., v.29, p.1174-1182, 2000.

FERRELL, C.L.; JENKINS, T.G. Body composition and energy utilization by steers of diverse genotypes fed a high concentrate diet during the finishing period: II. Angus, Boran, Brahman, Hereford, and Tuli Sires. J. Dairy Sci., v.76, p.647-657, 1998.

GETTY, R. Sisson and Grossman's the anatomy of the domestic animals. 5.ed. Philadelphia: W.B. Saunders, 1975. 1332p.

MELO, W.S.; VÉRAS, A.S.C.; FERRERIA, M.A. Cortes nobres, componentes do peso vivo e órgãos viscerais de bovinos mestiços de origem leiteira em condições de pastejo, restrito ou " $a d$ libitum". Rev. Bras. Cienc. Agrar., v.2, p.90-97, 2007.
OWENS, F.N.; DUBESKI, P.; HANSON, C.F. Factors that alter the growth and development of ruminants. J. Anim. Sci., v.71, p.3138-3150, 1993.

PERON, A.J.; FONTES, C.A.A.; LANA, R.P. et al. Tamanho dos órgãos internos e distribuição da gordura corporal em novilhos de cinco grupos genéticos, submetidos à alimentação restrita e $a d$ libitum. Rev. Bras. Zootec., v.22, p.813-819, 1993.

RIBEIRO, T.R.; PEREIRA, J.C.; LEÃO, M.I. et al. Tamanho de órgãos e vísceras de bezerros holandeses, para produção de vitelos recebendo dietas com diferentes níveis de concentrado. Rev. Bras. Zootec., v.30, p.2163-2168, 2001.

ROCHA, E.O. Estudo do desaleitamento precoce, exigências nutricionais e características produtivas de bovinos de origem leiteira, para corte. 1997. 151f. Tese (Doutorado em Zootecnia) - Universidade Federal Viçosa, Viçosa, MG.

SAALFELD, M.H. Uso da Silagem de colostro como substituto do leite na alimentação de terneiras leiteiras. Hora Vet., v.162, p.59-62, 2008.

SAALFELD, M.H.; PEREIRA, D.I.B.; SILVEIRA, K.R.K. et al. Anaerobically fermented colostrum: an alternative for feeding calves. Cienc. Rural, v.43, p.1636-1641, 2013.

SILPER, B.F. Efeitos de três estratégias de aleitamento sobre ganho de peso, desenvolvimento ruminal e perfil metabólico e hormonal de bezerros Holandeses. 2012. 96f. Dissertação (Mestrado em Zootecnia) - Escola de Veterinária, Universidade Federal de Minas Gerais, Belo Horizonte, MG.

SILVA, D.J.; QUEIROZ, A.C. Análise de alimentos: métodos químicos e biológicos. 3.ed. Viçosa: UFV, 2002. 235p.

Statistical Analysis Sistem-SAS Institute Inc. SAS® User's Guide: Statistics, Version 9 Edition. Cary, NC: SAS Institute Inc., 2002. 